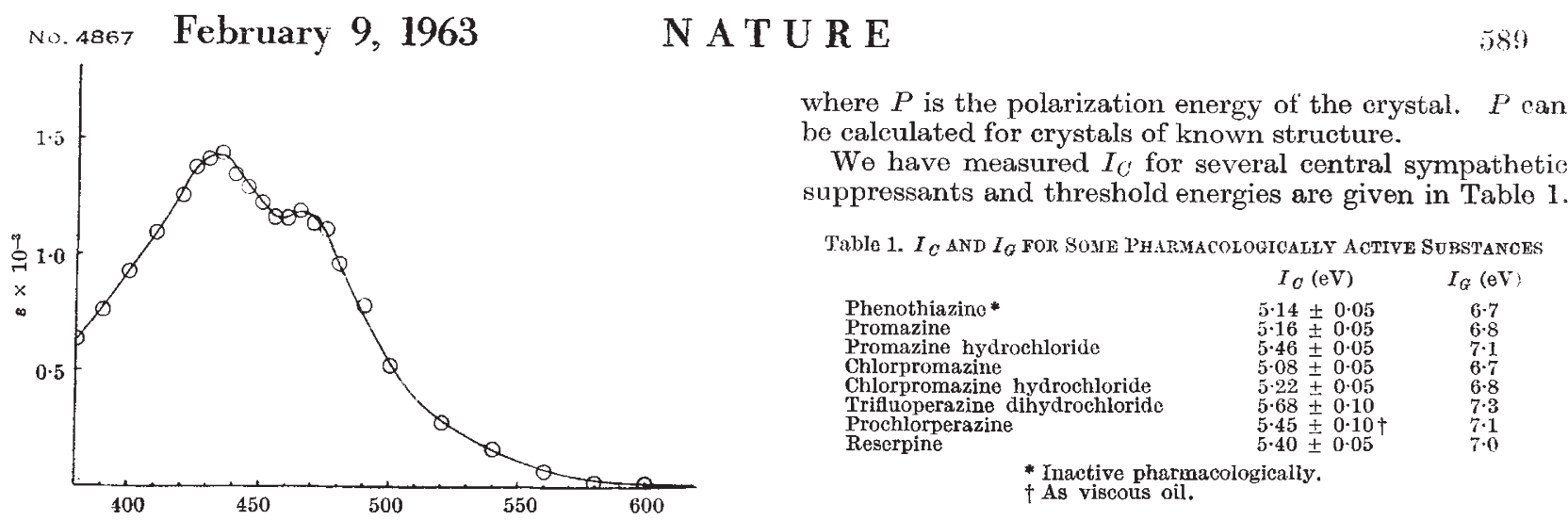

Fig. 2. Visible spectrum of nitrobenzene free radical anion in solution of $0.2 \mathrm{~N}$ sodium nitrate in dimethylformamide. Spectrum was made
for concentrations of the free radical anion of about $1 \cdot 3 \times 10^{-4} \mathrm{M}$ and for a cell length of $35 \mathrm{~mm}$

radical anion. By combining this with measurements of extinction for different wave-lengths caused by the presence of the free radical anion, the extinction coefficients of the whole spectrum were calculated.

The visible spectrum of nitrobenzene free radical anion exhibits two distinct maxima: the first is at $435 \mathrm{~m} \mu$ region and the second at $465 \mathrm{~m} \mu$ (Fig. 2).

The method applied by us for simultaneous measure. ments of the optical properties and oxidation current of the nitrobenzene free radical anion can be used for determ. ining the extinction coefficients and spectra of different free radical anions which are stable, or which only slowly decay with time. This method also enables the measure. ment of the kinetics of the decay of radical anions to be made.

WikTor Kemula Roman SIODA

Institute of Physical Chemistry,

Polish Academy of Sciences, Warsaw.

${ }^{1}$ Kemula, W., and Sioda, R., Bull. Acad. Polon. Sci. (Seric Chimique), 10, No. 2,107 (1962).

${ }^{2}$ Kemula, W., and Sioda, R., Bull. Acad. Polon. Sci., (Serie Chimique) (in the press). ${ }^{3}$ Paul, D. E., Lipkin, D., and Weissman, S. I., J. Amer. Chem. Soc., 78,

' Balk, P., Hoijtink, G. J., and Schreuvs, J. W. H., Rec. Trav. Chim., 76, 813 (1957).

${ }^{5}$ Pointeau, R., and Favede, Mme., preprints of papers, $52-1$, the fifth intern. symposium on free radicals, Uppsala (July, 1961).

\title{
Electron-donating Properties of Central Sympathetic Suppressants
}

ELECTRON-TRANSFER reactions between organic substances have often been implicated in various biological processes $^{1-3}$. Recently, Karreman, Isenberg and Szent. Györgi ${ }^{4}$ have suggested that certain central sympathetic suppressants act by donating electrons on the inside of the electric double layer of the central nervous system. A consequence of this hypothesis would be that pharmacologically active substances should possess relatively low ionization potentials.

Although it has been inferred both from molecular orbital calculations ${ }^{4-6}$ and charge-transfer spectra ${ }^{7}$ that these substances should be good donors, as yet there have been no reports of ionization potentials of suppressants. Though the direct measurement of ionization potential is quite difficult, it is nevertheless possible to derive values of this quantity from photoelectric measurements on the solid.

The photoelectric threshold, $I_{C}$, of a molecular crystal has been shown ${ }^{8}$ to be related simply to the molecular ionization potential, $I_{G}$, by:

$$
I_{C}=I_{G}+P
$$

$I_{G}$ is estimated from equation (1) by assuming an average value for $P$ of $1.6 \mathrm{eV}$ (ref. 8 ). We expect the error in $P$ to be no greater than $0.3 \mathrm{eV}$.

The measurements indicate that these substances have striking electron-donating properties. Chlorpromazine is an even better donor than the readily oxidizable naphtha. cene for which $I_{C}=5.25 \mathrm{eV}$ (ref. 9) and $I_{G}=6.88 \mathrm{eV}$ (ref. 10). Low values of $I_{C}$ for phenothiazine derivatives are seen to be associated with the parent nucleus.

Though it is appreciated that alternative mechanisms of suppression of the central nervous functions are feasible, the present work is consistent with the electron-transfer theory. It must be emphasized, however, that the possession of a low ionization potential does not in itself render a substance pharmacologically active. Phenothiazine, for example, is not a central sympathetic suppressant.

Since such biochemically important molecules as the chlorophylls and $\beta$-carotene also have low values of $I_{C}$ (ref. 11) it is still possible to maintain that electrontransfer reactions may be of importance in many biological processes.

We thank Prof. S. E. Wright, Mrs. R. Temple and Dr. W. J. O'Reilly for useful discussions.

Department of Physical Chemistry, University of Sydney.

${ }^{1}$ Bradley, D. F., and Calvin, M., Proc. U.S. Nat. Acad. Sci., 41, 563 (1955). 2 Platt, J. R., Science, 129, 372 (1959).

'Pullman, B., and Pullman, A., Rev. Mod. Phys., 32, 428 (1960).

4 Karreman, G., Isenberg, I., and Szent-Györgi, A., Science, 130, 1191 (1959).

'Pullman, B., and Pullman, A., Proc. U.S. Nat. Acad. Sci., 44, 1197 (1958). ${ }^{5}$ Orloff, M. K., and Fitts, D. D., Biochim. Biophys. Acta, 47, 596 (1961).

- Beukers, R., and Szent-Györui, A., Rec. Trav. Chim., 81, 255 (1962).

- Lyons, L. E., and Mackie, J. C., Proc. Chem. Soc., 71 (1962). ${ }^{9}$ Lyons, L. E., and Morris, G. C., J. Chem. Soc., 5192 (1960). ${ }^{10}$ Vilesov, F. I., Doklady Akad. Nauk S.S.S.R., 132, 632 (1960).

11 Terenin, A. N., Proc. Chem. Soc., 321 (1961).

\section{Photoconductivity of Manganous Phthalocyanine}

WE have investigated the dark- and photo-conductivity of single crystals of metal-free and some transition metal phthalocyanines. Some of our results for metal-free, zinc, copper, nickel and cobalt phthalocyanines have been published elsewhere ${ }^{1}$. Meanwhile wo have extended our investigations to include ferrous and manganous phthalocyanines. Here we wish to report briefly that we have found manganous phthaloeyanine to differ in its behaviour from the other members of the series in a striking manner. The measurements were made on the needle-shaped crystals using two electrodes. No guard ring was used, and the arrangement is therefore equivalent to a surface conductivity cell.

First, we find the dark resistivity of the manganous compound is much lower than that of the other phthalocyanines. The dark resistivities are presented in Table 1 , from which it can be seen that while manganous phthalocyanine has a specific resistivity as low as $10^{6}$ ohms/c.c., 